\title{
Introduction of a standardised protocol, including systematic use of tranexamic acid, for management of severe adult trauma patients in a low-resource setting: the MSF experience from Port-au-Prince, Haiti
}

Alessandro Jachetti ${ }^{1,2^{*}}$ (D), Rose Berly Massénat ${ }^{1}$, Nathalie Edema', Sophia C. Woolley ${ }^{1}$, Guido Benedetti ${ }^{1,3}$, Rafael Van Den Bergh ${ }^{3}$ and Miguel Trelles ${ }^{4}$

\begin{abstract}
Background: Bleeding is an important cause of death in trauma victims. In 2010, the CRASH-2 study, a multicentre randomized control trial on the effect of tranexamic acid (TXA) administration to trauma patients with suspected significant bleeding, reported a decreased mortality in randomized patients compared to placebo. Currently, no evidence on the use of TXA in humanitarian, low-resource settings is available. We aimed to measure the hospital outcomes of adult patients with severe traumatic bleeding in the Médecins Sans Frontières Tabarre Trauma Centre in Port-au-Prince, Haiti, before and after the implementation of a Massive Haemorrhage protocol including systematic early administration of TXA.
\end{abstract}

Methods: Patients admitted over comparable periods of four months (December2015- March2016 and December2016 - March2017) before and after the implementation of the Massive Haemorrhage protocol were investigated. Included patients had blunt or penetrating trauma, a South Africa Triage Score $\geq 7$, were aged 18-65 years and were admitted within $3 \mathrm{~h}$ from the traumatic event. Measured outcomes were hospital mortality and early mortality rates, in-hospital time to discharge and time to discharge from intensive care unit.

Results: One-hundred and sixteen patients met inclusion criteria. Patients treated after the introduction of the Massive Haemorrhage protocol had about 70\% less chance of death during hospitalization compared to the group "before" (adjusted odds ratio $0.3,95 \%$ confidence interval $0.1-0.8$ ). They also had a significantly shorter hospital length of stay $(p=0.02)$.

Conclusions: Implementing a Massive Haemorrhage protocol including early administration of TXA was associated with the reduced mortality and hospital stay of severe adult blunt and penetrating trauma patients in a context with poor resources and limited availability of blood products.

Keywords: Trauma, Tranexamic acid, Emergency room, Low-resource setting, Haiti, Medécins sans Frontières

\footnotetext{
*Correspondence: alessandro.jachetti@policlinico.mi.it

'Médecins Sans Frontières - Operational Centre Brussels - Haiti Mission,

Port-au-Prince, Haiti

'Emergency Department, Fondazione IRCCS Ca' Granda Ospedale Maggiore

Policlinico, Milan, Italy

Full list of author information is available at the end of the article
}

(c) The Author(s). 2019 Open Access This article is distributed under the terms of the Creative Commons Attribution 4.0 International License (http://creativecommons.org/licenses/by/4.0/), which permits unrestricted use, distribution, and reproduction in any medium, provided you give appropriate credit to the original author(s) and the source, provide a link to the Creative Commons license, and indicate if changes were made. The Creative Commons Public Domain Dedication waiver (http://creativecommons.org/publicdomain/zero/1.0/) applies to the data made available in this article, unless otherwise stated. 


\section{Background Introduction}

Tranexamic acid (TXA) is a synthetic lysin-analog that inhibits fibrinolysis by blocking the lysine-binding sites on plasminogen. The use of TXA was first described in the early 1970s for the control of bleeding associated with urinary tract surgery [1] and for haemorrhage associated with dental extraction in patients with haemophilia [2]. In the 1990s, TXA use was expanded to the treatment of hyper-fibrinolysis associated with cardiopulmonary bypass, in which it was proved to reduce blood loss and the need for transfusion [3-5]. Further studies on gynaecological bleeding $[6,7]$ and elective orthopaedic and abdominal surgery found that TXA reduced the need for transfusions $[8,9]$. The number of studies on the use of TXA in elective surgery has increased since the 2000s, providing adequate evidence of its safety profile $[10,11]$. Recent studies have confirmed how TXA can reduce overall mortality, blood loss, and mortality related to bleeding in many types of elective surgery, without observable adverse effects [12-18].

Bleeding is an important cause of death after trauma $[19,20]$. In 2010, the Clinical Randomization of an Antifibrinolytic in Significant Haemorrhage (CRASH-2) study, a multicentre randomized clinical trial on the effect of TXA administration to trauma patients with suspected significant bleeding, reported a decreased mortality in patients randomized to TXA as compared to a placebo [21]. Since the CRASH-2 study, the number of studies related to the use of TXA in trauma setting has increased. Many recent studies and systematic reviews confirmed the findings of the CRASH-2 study, thus prompting many hospitals in different settings to adopt TXA in their massive haemorrhage control protocols [22-24]. The use of TXA was further explored in paediatric trauma $[25,26]$ and prehospital settings [27, 28], showing reduced mortality and no side effects. TXA was also tested in military settings in 2012, with a first research known as the MATTERs study [29], followed by others [30-32], with results for combat casualties also holding promise. In 2016, the European Guidelines for Management of Major Bleeding recommended the use of TXA in trauma [33].

\section{Trauma induced coagulopathy}

Trauma is one of the major causes of morbidity and mortality at global level, especially among the young. Approximately 1.2 million trauma-related deaths occur annually, while the numbers of hospitalized patients (around 24 million) and patients who require extra-hospital medical care (around 84 million) are increasing, which adversely impacts healthcare resources. Haemorrhage is the most important cause of death in severe trauma victims, through two main mechanisms: fatal haemorrhage from vascular injury resulting in haemorrhagic shock, and secondary bleeding coagulopathy. The latter represents a pathological entity by itself, and is also termed Trauma Induced Coagulopathy (TIC) or Acute Trauma Coagulopathy (ATC). About 25$35 \%$ of trauma patients develop a clinically detectable and demonstrable coagulopathy even before hospital arrival, and they have a risk of death within $24 \mathrm{~h}$ that is up to eightfold higher than patients without signs of coagulopathy. The mechanisms underlying this process have not yet been fully clarified [34, 35]. Shock and systemic hypoperfusion could be triggers [36]. Considering hemodilution, recent studies only show significant association between prehospital fluid administration and onset of coagulopathy for infusion volumes greater than $2200 \mathrm{ml}$ [37-39]. The effect of hypothermia on coagulant proteases is minimal for temperatures above $33^{\circ} \mathrm{C}$ but a certain level of correlation with the onset of coagulopathy was observed [40-43]. Acidosis has a dose-dependent effect on the coagulation function. However, the normalization of $\mathrm{pH}$ do not result in reversing the coagulopathy, and more complex mechanisms underlying TIC may exist [44-46]. Each hospital should develop, implement and adhere to a management protocol, adapted to the local setup $[29,47,48]$.

\section{General setting}

Haiti is a Caribbean country, with a population of more than 10 million inhabitants, approximately $25 \%$ of whom live in the metropolitan area of the capital Port-au-Prince [49]. The country suffers from poor health indicators, lacks adequate resources and infrastructure, and struggles to meet the population's basic medical needs and to provide adequate services, such as maternal healthcare and acute trauma care. While a segment of the population can access private health services in Haiti or overseas, healthcare is generally difficult to access for a large proportion of Haitians. Medical facilities are often understaffed and lack funding to cover for medical supplies and operating costs.

The Médecins Sans Frontières (MSF) Tabarre hospital in Port-au-Prince, Haiti, is a referral Trauma Centre operating in a low-resource context, where bleeding and TIC are among the leading causes of death for victims of accidental and violent trauma. Blood transfusion is not readily available in this context, and the early administration of TXA may therefore contribute to saving lives and optimizing resources. This study aimed to assess the clinical and hospital outcomes of adult patients with severe traumatic bleeding in the MSF Tabarre Trauma Centre before and after the implementation of a new Massive Haemorrhage protocol, which included early administration of TXA.

\section{Methods}

MSF Tabarre trauma Centre

In Tabarre, a densely populated suburb of Port-au-Prince, MSF has been running a 121-bed hospital providing surgery and trauma-related care since 2012. In 2015, the Emergency 
Department (ED) was attended by more than 13,000 patients, and the hospital performed more than 8200 surgical interventions for 6400 patients [50]. Physiotherapy, mental health and social support were also offered to victims of trauma. The hospital was built to respond to the lack of adequate treatment for surgical and traumatic emergencies in the capital city after the 2010 earthquake.

\section{The south African triage score}

The South African Triage Score (SATS) was developed in 2006 for use in both pre- and in-hospital emergency units throughout South Africa. It aimed to address the increasing burden of severe emergency cases, medical staff shortages, and limited resources. The score was validated in emergency care by studies in South Africa [51, 52] and in various settings such as Malawi [53], Botswana [54], Ireland [55], and Pakistan [56]. As one of the few triage scores validated specifically in poorly resourced settings [57], MSF applied the SATS since the opening of Tabarre hospital. The SATS score is based on vital signs, mobility and level of consciousness (see Fig. 1) and due to its characteristics, its reliability and capacity to anticipate in-hospital mortality $[58,59]$ were chosen as measure of injury severity. The ISS (Injury Severity Score), the most widespread measure of injury severity in high-resource settings, was impractical in the setting of this study due to its dependence on anatomical scoring evaluation using parameters that could not be measured in this setting, and due to its poor reliability due to the different backgrounds of the MSF surgeons.

\section{Massive Haemorrhage protocol}

In late 2014, the MSF Critical Care Working Group elaborated the Massive Haemorrhage protocol (see Additional file 1). This protocol describes the actions to be taken in case of suspected haemorrhages: maintaining normothermia and haemostasis, resuscitation with permissive hypotension (systolic blood pressure $90 \mathrm{mmHg}$ ), early transfusion, and rapid access to the Operating Theatre $(\mathrm{OT})$. The protocol also recommends the early intravenous (IV) administration of $1 \mathrm{~g}$ of TXA in $10 \mathrm{~min}$, if possible and maximally within $3 \mathrm{~h}$ after injury, followed by $1 \mathrm{~g}$ IV of TXA in $10 \mathrm{~min}, 3 \mathrm{~h}$ after the $1 \mathrm{st}$ bolus. The protocol was introduced in Tabarre in December 2016 as part of a strategy aiming to maximise hospital resources and to strengthen the skills of the staff. The number of doctors working at the ED was doubled in April 2016 and all staff (doctors, nurses, auxiliary service) received additional training on trauma management and the use of TXA in October and November 2016.

\section{Study design and population}

This was a descriptive retrospective 'before and after' unpaired study measuring the clinical outcomes of adult patients with severe traumatic bleeding in the MSF Tabarre Trauma Centre. The outcomes of patients accessing the hospital over 4 months before the implementation of the Massive Haemorrhage protocol (December 2015 to March 2016, group "before") were compared with the outcomes of patients accessing the hospital over the same period one year after (December 2016 to March 2017, group "after"). This was a retrospective analysis of routinely collected data. Included cases were adults aged 18-65 years, with blunt or penetrating trauma and a SATS score $\geq 7$, arriving at the ED within $3 \mathrm{~h}$ from trauma and being classified as "red" codes.

\section{Data handling and analysis}

Data was sourced from the routinely implemented monitoring and surveillance databases (line-lists) and patient files at MSF Tabarre Trauma Centre. Exposure variables for the groups "before" and "after" included demographic (age), clinical (type of trauma, delay since trauma, SATS score) and case management (type of referral, time of access, Massive Haemorrhage protocol) characteristics of patients accessing the MSF Tabarre Trauma Centre (ED, OT, in-patient department and intensive care unit). Included patients were categorised as

\begin{tabular}{|c|c|c|c|c|c|c|c|c|}
\hline \multicolumn{9}{|c|}{ ADUL TRIAGE SCORE (over 12 years old / taller than $150 \mathrm{~cm}$ ) } \\
\hline & 3 & 2 & 1 & $\mathbf{0}$ & 11 & 2 & 3 & \\
\hline Mobility & & & & Walking & With help & Stretcher & & Mobility \\
\hline RR & & $<9$ & & $9-14$ & $15-20$ & $21-29$ & $>29$ & RR \\
\hline HR & & $<41$ & $41-50$ & \multirow{2}{*}{$\frac{51-100}{101-190}$} & $101-110$ & $111-129$ & $>129$ & HR \\
\hline SBP & $<71$ & $71-80$ & $81-100$ & & & $>199$ & & SBP \\
\hline Temp & & $<35$ & & $35-38.4$ & & $>38.4$ & & Temp \\
\hline AVPU & & Confused & & Alert & Verbal & Pain & Unresp. & AVPU \\
\hline Trauma & & & & No & Yes & & & Trauma \\
\hline \multicolumn{2}{|c|}{ Colour } & RFD & \multicolumn{2}{|c|}{ ORGANGE } & YEIU OW & \multicolumn{2}{|c|}{ GREEN } & DIfIC \\
\hline \multicolumn{2}{|c|}{ Score } & $\geq 7$ & $5-6$ & & $\frac{1 E L L W V}{3-4}$ & $\begin{array}{r}\text { GREE } \\
0-2\end{array}$ & & $\frac{\text { BLUE }}{\text { Dead }}$ \\
\hline
\end{tabular}

Legend: RR: respiratory rate, HR: heart rate, SBP: systolic blood pressure, Temp: temperature, AVPU: alertverbal-pain-unconscious scale

Fig. 1 SATS score (adapted from South African Triage Group 2008@). Legend: RR: respiratory rate, HR: heart rate, SBP: systolic blood pressure, Temp: temperature, AVPU: alert-verbal-pain-unconscious scale 
self-referred (yes or no), arrived $\leq />1 \mathrm{~h}$ from trauma, having penetrating or blunt trauma, having multiple injuries, undergoing surgery (yes or no). Outcomes included intra-hospital mortality (yes or no), early mortality (yes or no, considered as death within $48 \mathrm{~h}$ from arrival), number of days spent in the hospital (inpatient department and intensive care unit). Data was extracted and imported into a dedicated structured electronic spreadsheet (Excel 2010, Microsoft Corp, Redmond, WA, USA). All exposures and mortality outcomes were categorical and summarised as counts and proportions. Duration of hospitalisation was a numerical continuous outcome, and was summarized as median and interquartile range (IQR). Associations between exposures and the two groups ("before" and "after") were measured by Fisher's exact test. Associations between the duration of hospitalization and the two groups ("before" and "after") were measured by Wilcoxon rank sum test, first including the entire study population and secondarily considering only patients with favourable outcome (alive at exit) from hospital. The strength of association among exposures, the two study groups ("before" and "after"), the mortality causes and outcome (alive or dead at exit from hospital) were measured by bivariate and multivariate logistic regression and were expressed as odds ratios (ORs) and 95\% Confidence Intervals $(\mathrm{CI}) . P$-values $<0.05$ were considered statistically significant. Analysis was performed with STATA/IC Version 14.1. (StatCorp, College Station, TX, USA).

This study fulfilled the exemption criteria set by the MSF Ethics Review Board (ERB) for a posteriori analyses of routinely collected data and was approved by the Haitian Ethics Review Board.

\section{Results}

Overall, 116 patients met the inclusion criteria: 52 from the group "before" the introduction of the Massive Haemorrhage protocol, and 64 from the group "after". Table 1 shows a cascade of the included patients per group. The median age for the group "before" was 28 years [IQR 23-

Table 1 Number of patients included in the study by group (before and after)

\begin{tabular}{lll}
\hline & Group Before & Group After \\
& $12,2015-03$, & $12,2016-03$, \\
& 2016 & 2017 \\
\hline Accessed Emergency Department & 4559 & 5330 \\
SATS score $\geq 7$ & 1119 & 1528 \\
Age 18-65 years & 885 & 1170 \\
Blunt/penetrant trauma & 193 & 204 \\
Arrival $\leq 3$ h from trauma & 153 & 126 \\
Received Massive Hemorrhage protocol & n.a. & 70 \\
Red cases $^{\text {a }}$ retained for analysis & 52 & 64 \\
\hline
\end{tabular}

SATS: South Africa Triage Scale - according to SATS score
36], while it was 32 years [IQR 26-41] for the group "after". The female/male ratio was 0.1 and 0.2 respectively in the two groups. In the "before" group, 6 patients had blunt trauma as consequence of traffic accident and 46 had a penetrating trauma (40 gunshot wounds and 6 knife wounds). In the "after" group, 7 patients had blunt trauma (6 traffic accidents and 1 fall) and 57 had a penetrating trauma (46 gunshot wounds and 11 knife wounds). The two groups were similar in terms of characteristics of trauma (Table 2). However, patients treated after the introduction of the Massive Haemorrhage protocol had a significantly longer delay between the time of trauma and the time of arrival $(p<0.001)$ and they underwent less surgical treatment $(p<0.01)$ than the others.

The two groups showed similar hospital lengths of stay in the in-patient department and intensive care unit. When excluding patients with unfavourable outcome (i.e. event of death), patients treated after the introduction of the Massive Haemorrhage protocol had a significantly shorter hospital length of stay: 6 days [IQR 4-9] vs 8 [6-12] $(p=0.02)$.

In the group "before", 18 deaths were observed, 16 for bleeding (89\%, OR 0.5 95\%CI 0.0-7.6), 1 for sepsis and 1 for severe traumatic brain injury. In the group "after", 10 deaths were observed, 9 for bleeding (90\%, OR 0.3, 95\% CI $0.0-23$ ) and 1 for severe brain injury associated with blunt trauma. Out of all unfavourable outcomes, early mortality was recorded in 13 cases for the group "before" (72\%) and in 8 cases for the group "after" (80\%), OR 1.5 95\%CI $0.2-20$. Table 3 describes factors associated with unfavourable outcome in the entire study population. Patients exposed to the Massive Haemorrhage protocol (group "after") had 70\% lower odds of death during hospitalization compared to the group "before" (adjusted OR 0.3, 95\%CI 0.1-0.8). In a multivariate model, cases of blunt trauma were associated with the death of patients as compared to other kinds of trauma (adjusted OR 9.2, 95\%CI 2.4-35.4).

\section{Discussion}

To the best of our knowledge, this is the first study investigating the standardized approach and the systematic use of TXA in a referral third level trauma centre operating in a context of urban violence, lack of pre-hospital medical care, poor resources and with no capacity of massive systematic blood transfusion. The MSF Tabarre Trauma Centre, with its high caseload of severe traumatic bleeding injuries, allowed to evaluate the outcomes related to the implementation of a Massive Haemorrhage protocol including the early administration of TXA. The study showed favourable outcomes for patients after the implementation of the protocol.

Available evidence on the use of TXA mostly comes from high-resource settings. Studies from low-resource 
Table 2 Trauma characteristics and case management of patients by group (before and after)

\begin{tabular}{|c|c|c|c|}
\hline & Group Before & Group After & $P$-value* \\
\hline & 12, 2015-03, 2016 & 12, 2016-03, 2017 & \\
\hline & $n=52$ & $n=64$ & \\
\hline & count (\%) & count (\%) & \\
\hline Auto referral & $34(65.4)$ & $40(62.5)$ & 0.85 \\
\hline Referred & $18(34.6)$ & $24(37.5)$ & \\
\hline Arrived $\leq 1 \mathrm{~h}$ from trauma & 31 (59.6) & $15(23.4)$ & $<0.001$ \\
\hline Arrived $>1 \mathrm{~h}$ from trauma & $21(40.4)$ & 49 (76.6) & \\
\hline Penetrant trauma & $37(71.2)$ & $33(51.6)$ & 0.04 \\
\hline Blunt trauma & $15(28.8)$ & $31(48.4)$ & \\
\hline Multiple injuries & $28(53.9)$ & $32(50)$ & 0.71 \\
\hline No multiple injuries & $24(46.1)$ & $32(50)$ & \\
\hline Undergone surgery & $45(91.8)$ & $43(67.2)$ & $<0.01$ \\
\hline No surgery & $4(8.2)$ & $21(32.8)$ & \\
\hline *Fisher exact test & & & \\
\hline All patients & Group Before & Group After & $P$-value $* *$ \\
\hline & 12, 2015-03, 2016 & 12, 2016-03, 2017 & \\
\hline & $n=52$ & $n=64$ & \\
\hline & median [IQR] & median [IQR] & \\
\hline Time in-patient department & $5[4-9]$ & $4.5[3-8]$ & 0.18 \\
\hline Time intensive care & $4[1-6]$ & $4[2-6]$ & 0.40 \\
\hline Overall time in hospital & 8 [4-11] & 6 [3-9] & 0.23 \\
\hline **Wilcoxon rank sum test & & & \\
\hline Alive only & Group Before & Group After & $P$-value ${ }^{* *}$ \\
\hline & 12, 2015-03, 2016 & 12, 2016-03, 2017 & \\
\hline & $n=52$ & $n=64$ & \\
\hline & median [IQR] & median [IQR] & \\
\hline Time in-patient department & 5 [4-9] & $4.5[3-8]$ & 0.18 \\
\hline Time intensive care & $4[1-6]$ & $5[2-6]$ & 0.52 \\
\hline Overall time in hospital & 8 [6-12] & $6[4-9]$ & $0.02^{\mathrm{a}}$ \\
\hline
\end{tabular}

${ }^{*}$ Fisher Exact Test **Wilcoxon rank sum test; ${ }^{a}$ significantly associated

contexts (e.g. the CRASH-2 [21] study) typically considered settings where transfusion was available.

TXA dosage after trauma is $1 \mathrm{~g}$ IV in $10 \mathrm{~min}$, followed by another gram in $8 \mathrm{~h}$, as available in literature [21,33]. Such a dosage was validated for elective surgery [60-62] and at the time of writing no attempts to evaluate other dosages have been made in civilian trauma settings. Some studies in orthopaedic surgery demonstrated the efficacy of a bolus of TXA in different doses (from $15 \mathrm{mg} / \mathrm{Kg}$ to $30 \mathrm{mg} / \mathrm{Kg}$ ) instead of continuous infusion [63-66].

In a military context, the MATTERs study [29] proposed a single IV gram of TXA to be infused as soon as possible after trauma and a second gram within $24 \mathrm{~h}$; however, that analysis was not stratified by dose.

The MSF protocol included $1 \mathrm{~g}$ IV in $10 \mathrm{~min}$ upon arrival and $1 \mathrm{~g}$ after $3 \mathrm{~h}$, but no similar indications were found in the literature. Other humanitarian non-governmental organizations have proposed the use of TXA in their trainings but no protocol is available. The dose proposed by MSF reflects the difficulties to have $8 \mathrm{~h}$ of infusion and adequate devices in its operational contexts.

Considering all the above, the high caseload, and the high mortality rate of severe bleeding from blunt or penetrating trauma in the MSF Tabarre Trauma Centre, where massive transfusion is difficult, justified this evaluation.

The capacity, size and equipment of the ED of Tabarre Trauma Centre underwent virtually no change between December 2015 and March 2016 (group "before"). In April 2016, MSF doubled the number of Emergency doctors on day and night shifts, but did not change its approaches and protocols until the introduction of the Massive Haemorrhage protocol. Even with two ER doctor on shift, no 
Table 3 Factors associated with favorable or unfavorable outcome of patients

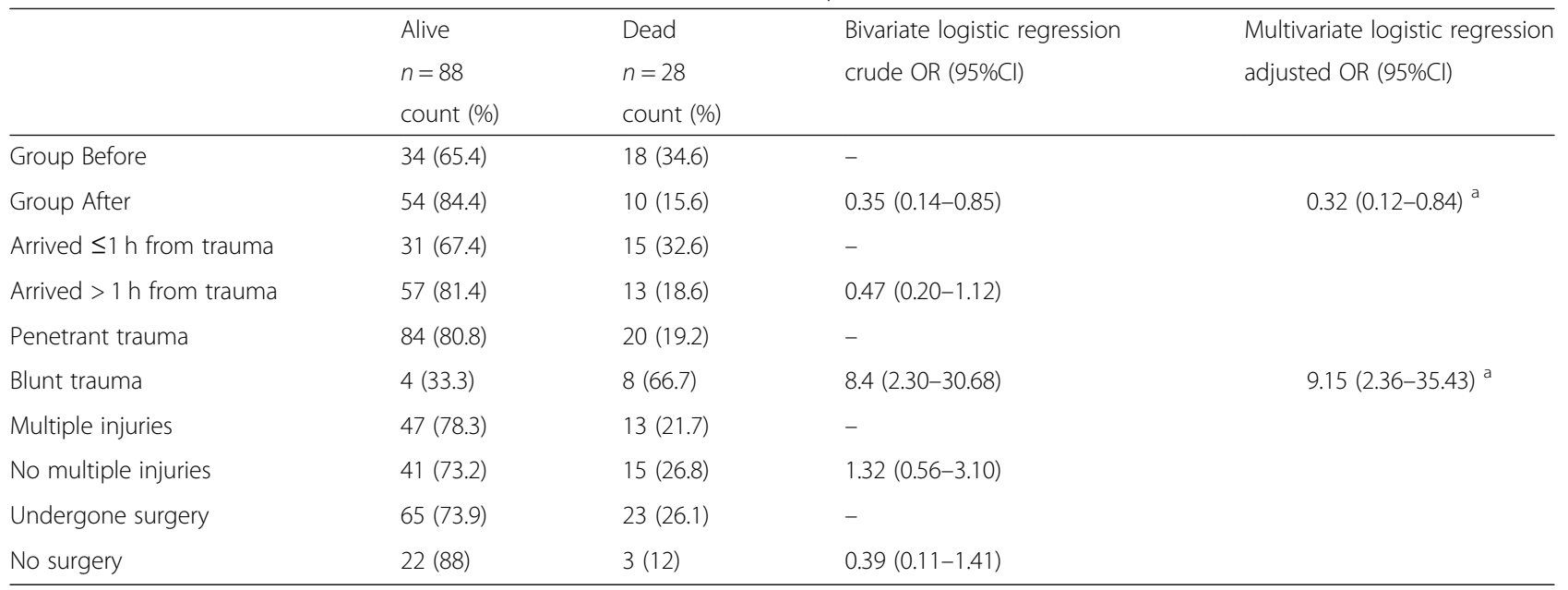

${ }^{a}$ significantly associated

difference in the admission time for severe patients was observed. No changes in the OT setting were implemented in the study period. Training was performed throughout 2016 by organizing scientific days and bedside coaching. Specific trainings on the protocol and the use of TXA in trauma were performed just before the implementation of the protocol.

No secondary or adverse effects after infusion of TXA were registered during this study, confirming the TXA safety profile. Our findings will support the implementation of the protocol, which is now promoted across MSF surgical and trauma projects.

\section{Limitations}

The "before" and "after" groups showed a few differences: patients treated after the protocol underwent less surgery than the "before" group patients. The higher prevalence of blunt trauma, which does not necessarily require surgical care, could justify this difference. Also, the "after" group showed a longer delay between the event of trauma and arrival at ED: as the increased delay would be expected to carry unfavourable effects, the positive results in the "after" group are likely an underestimation. Concerning all other exposures (demographic, clinical and case management) the two groups were similar.

Two comparable periods of four months were considered sufficiently long to mitigate the punctual effect of any operational change at OT level (e.g. the turnover of colleagues with different background, the exposure of staff to a single lecture on trauma management).

It was not possible to account for the effect of comorbidities on patients' outcome because these characteristics were not routinely recorded. However, the specific trauma target of the hospital and the median young age of the patients likely limit their relevance to our analysis.
Another limitation was the poor consistency of the registered delay between time of arrival at ED and case management, which was not available in most of the cases and was therefore excluded from analysis as an exposure.

In the "after" cohort, prehospital times of arrival to the ED after the injury had occurred were higher than in the "before" group, so reduced mortality could also be related to a higher mortality in the pre-hospital setting, which was not possible to account for in this study. Due to lack of Emergency Medical Services and due to the particular setting, obtaining data on pre-hospital care and mortality was impossible, but to our knowledge no changes in the prehospital handling between the two study periods occurred.

In the "after" cohort we observed a reduced surgery rate (92\% versus $67 \%$ ). It can lead to think that patient in the second cohort were less severe and it could explain the reduced mortality in this group, by the way according to severity score we were treating patient with the same severity and with the same probability of death. Moreover, the death rate for bleeding was similar in both groups, so we expect our cohorts to be similar in terms of population.

Finally, a certain number of eligible patients in the "after" group were not treated following the protocol. This was internally investigated by matching the marked therapies with the TXA vial consumption at ED, and by interviewing the doctors. The investigation demonstrated that the protocol was always respected and TXA administered in most cases, but was not recorded in the patient file. All such patients were excluded from analysis.

\section{Conclusions}

This study showed how a standardized approach for the care of severe adult blunt and penetrating trauma patients, including early TXA administration, was associated with reduced mortality in consequence of bleeding in a context with poor resources and not readily available massive blood 
transfusions. Results were in line with the literature on the use of TXA in severe trauma. Data showed that the dose of TXA used in the MSF protocol was effective, similarly to other dosages from developed countries. The difficulties to put in place massive transfusions in a low-resource setting did not appear to affect the capacity of TXA to contribute to preventing and mitigating $\mathrm{TIC}$, reducing mortality of severely injured trauma patients. More evidence is now required from similar contexts in order to better investigate the dosage and effect of TXA in severe trauma and to compensate for the limits of a monocentric study. Overall, the favourable outcomes of patients exposed to treatment in the "after" group should not be considered an effect of TXA alone. It was rather an effect of the implementation of the entire Massive Haemorrhage protocol (including the training of staff, an improved operational circuit, the availability of a trauma specialist, and the general standardization of the approach by the protocol). Moreover, TXA is not to be considered as a substitute of blood transfusions, which remain key to manage severe trauma. TXA is no "panacea" but an option to reduce the death toll in severe trauma. Its effect is logically more evident wherever adequate blood transfusion is not readily available, thus suggesting its relevance in low-resource settings. The implementation of this protocol was also associated with a reduced hospital stay, carrying additional benefits for patients and the hospital.

This study contributed to the evidence for using TXA as a component of trauma management packages. Together with its use in pre-hospital care (ambulances and first aid posts, as supported by recent literature [28-30]), the systematic use of TXA associated with adequate staff training and the standardisation of trauma care could mark a difference in the outcome of patients in lowresourced and precarious humanitarian contexts. Future studies in low-resources context should be performed to collect data and evaluate the impact of our actions. Standardized protocols should reduce mortality and improve efficiency of our medical project. Other actions and studies might be focus on the improvement of the of pre-hospital care system as a strategy to reduce the mortality of this patient population.

\section{Supplementary information}

Supplementary information accompanies this paper at https://doi.org/10. 1186/s12873-019-0266-x.

Additional file 1. Massive Haemorrhage protocol.

\section{Abbreviations}

ATC: Acute Trauma Coagulopathy; CRASH: Clinical Randomization of an Antifibrinolytic in Significant Haemorrhage; ED: Emergency Department; ICU: Intensive Care Unit; ISS: Injury Severity Score; LIC: Low Income Country; LuxOR: Luxembourg Operational Research; MSF: Médecins Sans Frontières; OCB: Operational Centre Brussels; OT: Operating Theatre; SATS: South African
Triage Score; TIC: Trauma Induced Coagulopathy; TXA: Tranexamic Acid; WHO: World Health Organisation

\section{Acknowledgements}

The Authors are thankful to all MSF staff (doctors, nurses, assistants) who helped them to implement the Massive Haemorrhage protocol in Tabarre, saving lives every day with passion and professionality.

\section{Authors' contributions}

AJ designed the study, collected and entered data, participated in the implementation of the Massive Haemorrhage protocol. RBM and NE helped in sharing the protocol between the staff, collected patients' data, conducted internal reviews, participated in the implementation of the Massive Haemorrhage protocol. AJ and GB analysed and interpreted the patient data, GB made the statistical analyse and tables. SCW cared about authorisation, ethical approval and overall coordination. MT implemented the protocol. MT, SCW and RVDB contributed in writing and reviewing the study protocol and cared about authorisations, ethical approval and overall coordination. All authors reviewed and approved the original protocol and the final manuscript.

\section{Funding}

Médecins Sans Frontières - Operational Centre Brussels covered all the expenses and costs for ethics approval and will cover the cost for publication.

\section{Availability of data and materials}

Data is property of MSF - Operational Centre Brussels. The datasets used and analysed during the current study are available from the corresponding author on reasonable request and upon approval of MSF - Operational Centre Brussels.

\section{Ethics approval and consent to participate}

This study obtained exemption from the MSF Ethics Review Board and the ethical approval from the Haiti Research Ethics Committee.

\section{Consent for publication}

Not applicable.

\section{Competing interests}

The authors declare that they have no competing interests.

\section{Author details}

${ }^{1}$ Médecins Sans Frontières - Operational Centre Brussels - Haiti Mission, Port-au-Prince, Haiti. 'Emergency Department, Fondazione IRCCS Ca' Granda Ospedale Maggiore Policlinico, Milan, Italy. ${ }^{3}$ Médecins Sans Frontières Operational Centre Brussels - Operational Research Unit, Brussels, Belgium. ${ }^{4}$ Médecins Sans Frontières - Operational Centre Brussels - Surgical and Critical Care Unit, Brussels, Belgium.

Received: 10 April 2019 Accepted: 12 September 2019

Published online: 18 October 2019

\section{References}

1. Bedil M. Use of tranexamic acid as hemostatic in oral surgery. Trib Odontol (B Aires). 1971;55(7):175-6.

2. Forbes CD, Barr RD, Reid G, Thomson C, Prentice CR, McNicol GP, Douglas AS. Tranexamic acid in control of haemorrhage after dental extraction in haemophilia and Christmas disease. Br Med J. 1972;2(5809):311-3.

3. Horrow JC, Hlavacek J, Strong MD, Collier W, Brodsky I, Goldman SM, Goel IP. Prophylactic tranexamic acid decreases bleeding after cardiac operations. J Thorac Cardiovasc Surg. 1990;99(1):70-4.

4. Horrow JC, Van Riper DF, Strong MD, Brodsky I, Parmet JL. Hemostatic effects of tranexamic acid and desmopressin during cardiac surgery. Circulation. 1991:84(5):2063-70.

5. Nakashima A, Matsuzaki K, Fukumura F, Hisahara M, Kanegae Y, Fukae K, Miyamoto K, Nishida T, Tokunaga S, Tominaga R, et al. Tranexamic acid reduces blood loss after cardiopulmonary bypass. ASAIO J. 1993;39(3):M185-9.

6. As AK, Hagen P, Webb JB. Tranexamic acid in the management of postpartum haemorrhage. Br J Obstet Gynaecol. 1996;103(12):1250-1. 
7. Bonnar J, Sheppard BL. Treatment of menorrhagia during menstruation: randomised controlled trial of ethamsylate, mefenamic acid, and tranexamic acid. BMJ. 1996:313(7057):579-82.

8. Benoni $\mathrm{G}$, Fredin H. Fibrinolytic inhibition with tranexamic acid reduces blood loss and blood transfusion after knee arthroplasty: a prospective, randomised, double-blind study of 86 patients. J Bone Joint Surg Br. 1996; 78(3):434-40.

9. Boylan JF, Klinck JR, Sandler AN, Arellano R, Greig PD, Nierenberg H, Roger SL, Glynn MF. Tranexamic acid reduces blood loss, transfusion requirements, and coagulation factor use in primary orthotopic liver transplantation. Anesthesiology. 1996;85(5):1043-8.

10. Takagi H, Manabe H, Kawai N, Goto S, Umemoto T. Aprotinin increases mortality as compared with tranexamic acid in cardiac surgery: a meta-analysis of randomized head-to-head trials. Interact Cardiovasc Thorac Surg. 2009;9:98-101.

11. Henry D, Carless P, Fergusson D, Laupacis A. The safety of aprotinin and lysine-derived antifibrinolytic drugs in cardiac surgery: a meta-analysis. CMAJ. 2009;180:183-93.

12. Madsen RV, Nielsen CS, Kallemose T, Husted H, Troelsen A. Low Risk of Thromboembolic Events After Routine Administration of Tranexamic Acid in Hip and Knee Arthroplasty. J Arthroplasty. 2016. https://doi.org/10.1016/j. arth.2016.10.015 [Epub ahead of print].

13. Fígar A, Mc Loughlin S, Slullitel PA, Scordo W, Buttaro MA. Influence of single-dose intravenous tranexamic acid on total hip replacement : a study on transfusions, collateral complications, and readmissions. Orthopade. 2016; [Epub ahead of print].

14. Myles PS, Smith JA, Forbes A, Silbert B, Jayarajah M, Painter T, Cooper DJ, Marasco S, McNeil J, Bussières JS, McGuinness S, Byrne K, Chan MT, Landoni G, Wallace S. ATACAS Investigators of the ANZCA Clinical Trials Network. Tranexamic Acid in Patients Undergoing Coronary-Artery Surgery. N Engl J Med. 2016; [Epub ahead of print].

15. Aziz M, Mahmood SB, Lakdawala RH, Ahmad T. Lower red cell transfusion rates with use of tranexamic acid in single-stage bilateral total knee arthroplasty: A retrospective audit. J Pak Med Assoc. 2016;66((Suppl 3)(10)):S102-5.

16. Hallstrom B, Singal B, Cowen ME, Roberts KC, Hughes RE. The Michigan experience with safety and effectiveness of Tranexamic acid use in hip and knee Arthroplasty. J Bone Joint Surg Am. 2016;98(19):1646-55.

17. Lozano M, Basora M, Peidro L, Merino I, Segur JM, Pereira A, Salazar F, Cid J, Lozano L, Mazzara R, Macule F. Effectiveness and safety of tranexamic acid administration during total knee arthroplasty. Vox Sang. 2008;95(1):39-44.

18. Henry DA, Carless PA, Moxey AJ, O'Connell D, Stokes BJ, McClelland B, Laupacis A, Fergusson D. Anti-fibrinolytic use for minimising perioperative allogeneic blood transfusion. Cochrane Database Syst Rev. 2007:4:CD001886 Review.

19. Oyeniyi BT, Fox EE, Scerbo M, Tomasek JS, Wade CE, Holcomb JB. Trends in 1029 trauma deaths at a level 1 trauma center: Impact of a bleeding control bundle of care. Injury. 2016; [Epub ahead of print].

20. Moore FA, McKinley BA, Moore EE. The next generation in shock resuscitation. Lancet. 2004;363:1988-96.

21. CRASH-2 trial collaborators, Shakur H, Roberts R, Bautista R, Caballero J, Coats T, Dewan Y, El-Sayed H, Gogichaishvili T, Gupta S, Herrera J, et al. Effects of tranexamic acid on death, vascular occlusive events, and blood transfusion in trauma patients with significant haemorrhage (CRASH-2): a randomised, placebo-controlled trial. Lancet. 2010;376(9734):23Y32.

22. CRASH-2 trial collaborators, Shakur H, Roberts R, Bautista R, Caballero J, Coats T, Dewan Y, El-Sayed H, Gogichaishvili T, Gupta S, Herrera J, et al. The importance of early treatment with tranexamic acid in bleeding trauma patients: an exploratory analysis of the CRASH-2 randomised controlled trial. Lancet. 2011;377:1096-101.

23. Cap AP, Baer DG, Orman JA, Aden J, Ryan K, Blackbourne LH. Tranexamic acid for trauma patients: a critical review of the literature. J Trauma. 2011;71:S9-S14.

24. Cole E, Davenport R, Willett K, Brohi K. Tranexamic acid use in Severly injured civilian patients and the effects on outcomes : a prospective cohort study. Ann Surgery. 2015;261(2):390-4

25. Eckert MJ, Wertin TM, Tyner SD, et al. Tranexamic acid administration to pediatric trauma patients in a combat setting: the pediatric trauma and tranexamic acid study (PED-TRAX). J Trauma Acute Care Surg. 2014;77:852-8.

26. Urban D, Dehaeck R, Lorenzetti D, Guilfoyle J, Poon MC, Steele MG, Lardner D, Wai Yan Ma I, Brindle ME. Safety and efficacy of tranexamic acid in bleeding paediatric trauma patients: a systematic review protocol. BMJ Open. 2016;6:e012947.

27. Ausset S, et al. Tranexamic acid as part of remote damage-controle resuscitation in the prehospital setting: a critical appraisal of the literature and available alternatives. J Trauma Acute Care Surg. 2015;78:S70YS75.
28. Wafaisade A, Lefering R, Bouillon B, Böhmer B, Gäßler M, Ruppert M, TraumaRegister DGU. Prehospital administration of tranexamic acid in trauma patients. Critical Care. 2016;20(143):1-9.

29. Morrison JJ, Dubose JJ, Rasmussen TE, Midwinter MJ. Military Applicatio of Tranexamic Acid in Trauma Emergency Resuscitation (MATTERs) study. Arch Surg. 2012;147(2):113Y119.

30. Lipsky A, Abramovich A, Nadler R, Feinstein U, Shaked G, Kreiss Y, Glassberg E, et al. Injury, Int. J. Care Injured. 2014:45:66-70.

31. Aedo-Martín D, Garcia-Canas R, Navarro-Suay R, Martínez-Roldàn M, BanosTurza R, Tamburri-Bariain R. Empleode ácido tranexámico en el herido de combate, experiencia de la sanidad militar espanola. Serie de casos y revisión de la literatura. RevEsp Cir Ortop Traumatol. 2016;60:200-5.

32. Lewis CJ, Li P, Stewart L, Weintrob AC, Carson ML, Murray CK, Tribble DR, Ross JD. Tranexamic acid in life-threatening military injury and the associated risk of infective complications. BJS. 2016;103:366-73.

33. Rossaint, et al. The European guideline on management of major bleeding and coagulopathy following trauma: fourth edition. Critical Care. 2016;20: $1001-55$.

34. Brohi K, Singh J, Heron M, et al. Acute traumatic coagulopathy. J Trauma. 2003;54:1127-30.

35. Schreiber MA. Coagulopathy in the trauma patient. Curr Opin Crit Care 2005;11:590-7.

36. Brohi K, Cohen JC, Davenport RA. Acute coagulopathy of trauma: mechanism, identification and effect. Curr Opin Crit Care. 2007;13:680-5.

37. Maegele $M$, Lefering $R$, Yucel $N$, et al. Early coagulopathy in multiple injury: an analysis from the German trauma registry on 8724 patients. Injury. 2007; 38:298-304.

38. Brazil EV, Coats TJ. Sonoclot coagulation analysis of in-vitro haemodilution with resuscitation solutions. J R Soc Med. 2000;93:507-10.

39. Coats TJ, Brazil E, Heron M, MacCallum PK. Impairment of coagulation by commonly used resuscitation fluids in human volunteers. Emerg Med J. 2006;23:846-9.

40. Farkash U, Lynn M, Scope A, et al. Does prehospital fluid administration impact core body temperature and coagulation functions in combat casualties? Injury. 2002;33:103-10.

41. Shafi S, Elliott AC, Gentilello L. Is hypothermia simply a marker of shock and injury severity or an independent risk factor for mortality in trauma patients? Analysis of a large national trauma registry. J Trauma. 2005;59:1081-5.

42. Wolberg AS, Meng ZH, Monroe DM, Hoffman M. A systematic evaluation of the effect of temperature on coagulation enzyme activity and platelet function. J Trauma. 2004;56:1221-8.

43. Meng ZH, Wolberg AS, Monroe DM, Hoffman M. The effect of temperature and $\mathrm{pH}$ on the activity of factor Vlla: implications for the efficacy of highdose factor Vlla in hypothermic and acidotic patients. J Trauma. 2003;55: 886-91.

44. Martini WZ, Pusateri AE, Uscilowicz JM, et al. Independent contributions of hypothermia and acidosis to coagulopathy in swine. J Trauma. 2005;58: 1002-9.

45. Engstrom M, Schott $U$, Romner B, Reinstrup P. Acidosis impairs the coagulation: a thromboelastographic study. J Trauma. 2006;61:624-8.

46. Martini WZ, Dubick MA, Pusateri AE, et al. Does bicarbonate correct coagulation function impaired by acidosis in swine? J Trauma. 2006;61:99-106.

47. Spahn DR, et al. Management of bleeding and coagulopathy following major trauma: an updated European guideline. Crit Care. 2013;17:R76.

48. Nardi $\mathrm{G}$, et al. Prevention and treatment of trauma induced coagulopathy $(\mathrm{TIC})$. An intended protocol from the Italian trauma update research group. J Anesthesiol Clin Sci. 2013;2:1-10. 2049-9752-2-22.

49. Population totale, population de 18 ans et plus menages et densitès éstimes en 2009, Institut National de Statistique et Informatique - Haiti. 2009.

50. MSF Activity report 2015, second edition.

51. Bruijns SR, Wallis LA, Burch VC. A prospective evaluation of the cape triage score in the emergency department of an urban public hospital in South Africa. Emerg Med J. 2008;25:398-402.

52. Gottschalk SB, Wood D, DeVries S, et al. On behalf of the cape triage group. The cape triage score: a new triage system South Africa: proposal from the cape triage group. Emerg Med J. 2006;23:149-53.

53. Harrison H-L, Raghunath N, Twomey M. Emergency triage, assessment and treatment at a district hospital in Malawi. Emerg Med J. 2012;29:924-5.

54. Emmanuel A, Ismail A, Kellett J. Assessing the need for hospital admission by the cape triage discriminator presentations and the simple clinical score. Emerg Med J. 2010;27:852-5. 
55. Twomey M, Mullan C, Torrey S, Wallis L, Kestler A. The Princess Marina hospital accident and emergency triage scale provides highly reliable triage acuity ratings. Emerg Med J. 2012;29:650-3.

56. Dalwai MK, Tayler-Smith $\mathrm{K}$, Trelles M, Jemmy J-P, Maikéré J, Twomey M, Wakeel M, labal M, Zachariah R. Implementation of a triage score system in an emergency room in Timergara. Pakistan PHA. 2013;3(1):43-5.

57. Dalwai $\mathrm{M}$, et al. Is the south African triage scale valid for use in Afghanistan, Haiti an Sierra Leone? BMJ Glob Health. 2017;2:e000160.

58. Dalwai $\mathrm{M}$, et al. Inter-rater and intrarater reliability of the South African Triage Scale in low-resource settings of Haiti and Afghanistan. Emerg Med J. 2018;0:1-5.

59. Massaut, et al. The modified south African triage scale system for mortality prediction in resource constrained emergency surgical centres: a retrospective cohort study. BMC Health Serv Res. 2017;17:594.

60. Henry DA, Carless PA, Moxey AJ, O'Connell D, Stokes BJ, Fergusson DA, et al. Anti-fibrinolytic use for minimising perioperative allogeneic blood transfusion. Cochrane Database Syst Rev. 2011;3:1-208.

61. Fiechtner BK, Nuttall GA, Johnson ME, Dong Y, Sujirattanawimol N, Oliver WC Jr, et al. Plasma tranexamic acid concentrations during cardiopulmonary bypass. Anesth Analg. 2001;92:1131-6.

62. Horrow JC, Van Riper DF, Strong MD, Grunewald KE, Parmet MJ. The doseresponse relationship of tranexamic acid. Anaesthesiology. 1995;82:383-92.

63. Hiippala S, Strid L, Wennerstrand M, Arvela V, Mantyla S, Ylinen J, et al. Tranexamic acid (Cyklokapron) reduces perioperative blood loss associated with total knee arthroplasty. Br J Anaesth. 1995;74:534-7.

64. Maniar RN, Kumar G, Singhi T, Nayak RM, Maniar RP. Most effective regimen of tranexamic acid in knee arthroplasty: a prospective randomized controlled study in 240 patients. Clin Orthop Relat Res. 2012;470:2605.

65. Hourlier H, Reina N, Fennema P. Single dose intravenous tranexamic acid as effective as continuous infusion in primary total knee arthroplasty: a randomised clinical trial. Arch Orthop Trauma Surg. 2015;135:465-71.

66. Akgül T, Büget M, Salduz A, Edipoğlu IS, Ekinci M, Küçükay S, Şen C. Efficacy of preoperative administration of single high dose intravenous tranexamic acid in reducing blood loss in total knee arthroplasty: A prospective clinical study. Acta Orthopaedica et Traumatologica Turcica. 2016;50(4):429-31.

\section{Publisher's Note}

Springer Nature remains neutral with regard to jurisdictional claims in published maps and institutional affiliations.

Ready to submit your research? Choose BMC and benefit from:

- fast, convenient online submission

- thorough peer review by experienced researchers in your field

- rapid publication on acceptance

- support for research data, including large and complex data types

- gold Open Access which fosters wider collaboration and increased citations

- maximum visibility for your research: over $100 \mathrm{M}$ website views per year

At $\mathrm{BMC}$, research is always in progress.

Learn more biomedcentral.com/submissions 